\title{
La Revista de la Academia Colombiana de Ciencias Exactas, Físicas y Naturales y los 250 años del nacimiento de Francisco José de Caldas: una conmemoración
}

La enriquecedora experiencia que significó la publicación del Suplemento Clásicos 1936-1986 sigue dando frutos. En la antología que hoy ofrecemos con los artículos que sobre Francisco José de Caldas se publicaron en la Revista de la Academia durante sus 82 años de labores, los académicos y todos nuestros lectores podrán ampliar su conocimiento en torno a la vida y la obra del Sabio, como una forma de conmemorar los 250 años de su nacimiento.

La antología fue preparada magistralmente por el académico Alberto Gómez-Gutiérrez, editor asociado de la Revista y uno de los gestores del Suplemento Clásicos. En la revisión que realizó para dicho suplemento quedó claro que el trabajo de Francisco José de Caldas había sido exaltado en las páginas de la Revista en diversas ocasiones, especialmente por la labor de su primer editor, el doctor Jorge Álvarez Lleras. En este sentido, vale la pena recordar que la aparición del primer número de la Revista de la Academia coincidió con los 120 años del fallecimiento de Caldas. A finales del 2017 el académico GómezGutiérrez expresó su deseo de preparar la antología con ocasión de los 250 años del natalicio de Caldas en 2018, trabajo con el que se comprometió inmediatamente y que le tomó nueve meses, y en el cual tuve el gran privilegio de participar. Cinco de los 27 documentos que contiene la antología son de autoría de Caldas y aparecieron en los volúmenes 1, 2 y 8, publicados entre 1936 y 1950.

Como sustento de los resultados de la labor emprendida para dicha antología, vale la pena recordar los objetivos de la Revista de la Academia, especialmente a partir del pensamiento y las palabras de su primer editor, por lo cual me permito transcribir algunos apartes de sus Notas de la Dirección, aparecidas en algunos de los primeros números.

De la manera como habrá de continuarse esta Revista, dentro de los propósitos de la Academia

Notas de la dirección

Rev. Acad. Colomb. Cienc. Ex. Fis. Nat. 2(2): 95, 1937

Frecuentemente ha sucedido que nuestros historiadores — que no olvidan ni insignificantes detalles relativos a hombres públicos nuestros: prestigiosos militares, politicos de renombre, escritores y poetas de fama-dejaron en la penumbra, y a veces en plena oscuridad, a servidores de la Patria que la ilustraron con su ciencia en la cátedra retirada, en el silencio de los laboratorios o en las bibliotecas y museos. Y hasta ha ocurrido con figuras como la del sabio Caldas, cuyo nombre ha resonado desde la epopeya de nuestra independencia por todos los ámbitos del país, que al ser conocidos lo deben a sus hechos guerreros o a sus influencias políticas o sociales, nunca a sus méritos cientificos. Así, por ejemplo, en el caso de Caldas, es dificil saber si los historiadores que se han ocupado de su figura histórica de prócer y mártir de la Patria, comprendieron jamás cuál fue la importancia de su labor en el campo de la Física, o siquiera supieron a ciencia cierta en qué consistió ella. A remediar tal deficiencia, para que nuestra juventud pueda comprender que en el pasado Colombia ha contado con hombres de verdadero mérito cientifico, tiende el propósito firme de esta Revista de incluir en sus páginas los nombres todos de colombianos que en alguna circunstancia recorrieran el territorio patrio, observaran su fauna y su flora, descubrieran sus bellezas naturales, explotaran los filones de sus minas, trazaran sus horizontes geológicos, midieran la extensión de sus llanuras o la altura de sus montañas, analizaran en los laboratorios los productos de su suelo, o ilustraran a sus a sus compatriotas en los progresos de las matemáticas y sus aplicaciones.

Conceptos sobre la aparición de la Revista de la Academia Colombiana de Ciencias Exactas, Físico - Químicas y Naturales Notas de la dirección

Rev. Acad. Colomb. Cienc. Ex. Fis. Nat. 1(3): 300, 1937

Por disposición de la Academia, empezamos a publicar en la presente edición parte de la copiosa correspondencia recibida. Al hacerlo, dejamos constancia de nuestro agradecimiento por los honrosos conceptos contenidos en ella respecto a la labor emprendida por la Institución con la publicación de esta Revista. También insertamos en estas notas recortes de prensa de la capital y de provincias, referentes a la misma circunstancia.

"El Siglo". Febrero 27 de 1937.

A él [Álvarez Lleras] se ha encomendado la guarda de este templo de la ciencia latina que es el Observatorio de Bogotá y en cuyos muros parece que vivieran en acecho las sombras de Mutis, Caldas, Codazzi y Garavito. 
La Revista se ha presentado por el personal de dirección y redacción con un acopio de trabajos que desde hacía muchas decenas de años se hacía esperar por los estudiosos. En la mencionada Revista se darán a conocer los estudios cientificos relacionados con las ciencias exactas, las ciencias fisicoquímicas y las naturales. Estas tres secciones están integradas por lo más linajudo del pensamiento y del estudio. No cometemos error al afirmar que después de la publicación del "Semanario de la Nueva Granada", fundado y dirigido por Caldas, y auspiciado y alimentado con la contribución técnica del sabio alemán barón Alejandro de Humboldt en la primera década del siglo XIX, ninguna otra revista se presenta a la consideración de la juventud que desee estudiar como ésta de la Academia Colombiana de Ciencias Exactas, Físico-Químicas y Naturales. Para hondas meditaciones y para profundas elucubraciones del espíritu se presentan los señores que integran la dirección y redacción de la mencionada Revista, la única en su clase que está llamada a salvar la tradición de estudios serios que dio a Colombia una posición envidiable entro las naciones de la raza latina.

Y, a propósito de Caldas, muy modestamente nos permitimos insinuar a la directiva y redacción de la Revista se dé a conocer en ella, aunque sea por partes, ya que es muy extensa, la obra de nuestro Caldas. Qué gran favor prestaríais, señores de la dirección, a esta juventud que en todo piensa menos en estudiar y que de hacerlo tumultuariamente sostiene que los sabios no sirven para profesores, porque saben mucho.

Juan B. Arias

Como editora de la Revista de la Academia Colombiana de Ciencias Exactas, Físicas y Naturales, y en representación de su Comité Editorial, deseo expresar nuestro sincero agradecimiento al académico Gómez Gutiérrez por el excelente trabajo que adelantó y que enaltece a nuestra Revista. Constituye una gran satisfacción presentar a todos nuestros lectores este suplemento, el cual responde con creces a los anhelos que en torno a la figura de Caldas expresara desde el origen mismo de la Revista, hace 82 años, su primer editor: "Procurar que este genio de la ciencia colombiana sea conocido del público a través de sus obras. Si a esto sólo alcanzara la acción de esta Revista, nos daríamos por satisfechos".

Los invito a disfrutar esta magnífica antología, y a difundirla, especialmente entre las nuevas generaciones, para contribuir así al cumplimiento de uno de los objetivos de la Revista en sus 82 años de vida.

Elizabeth Castañeda, Ph.D.

Editora 